\title{
Estrogen Administration Negatively Alters Mood Following Monoaminergic Depletion and Psychosocial Stress in Postmenopausal Women
}

\author{
Paul A Newhouse*,', Julie Dumas', Catherine Hancur-Bucci', Magdalena Naylor', Cynthia K Sites², \\ Chawki Benkelfat ${ }^{3}$ and Simon $N$ Young ${ }^{3}$ \\ 'Clinical Neuroscience Research Unit, Department of Psychiatry, University of Vermont College of Medicine, Burlington, VT, USA; ${ }^{2}$ Department of \\ Obstetrics and Gynecology, University of Alabama School of Medicine, Birmingham, AL, USA; ${ }^{3}$ Department of Psychiatry, McGill University School \\ of Medicine, Montreal, QC, Canada
}

\begin{abstract}
Differences in the rates of affective disorders between women and men may relate to gender differences in gonadal steroid levels such as estrogen that have effects on brain monoamines important to mood regulation. Changes in estrogen secretion patterns during the perimenopause and menopause may be relevant to the increased risk for affective symptoms at that time. This study examined whether $17 \beta$-estradiol (E2) administration can modify the mood effects of experimental psychosocial stress following acute monoamine depletion in postmenopausal women. Subjects consisted of 15 normal postmenopausal women (PMW) (ages 67.I \pm II.2 years) blindly placed on either oral placebo or E2 ( $\mathrm{mg} /$ day for 1 month, then $2 \mathrm{mg} /$ day for 2 months). At the end of the 3-month treatment phase, subjects participated in three blinded depletion challenges in which they ingested each of three amino-acid mixtures: deficient in tryptophan, deficient in phenylalanine/tyrosine, or nutritionally balanced. After $5 \mathrm{~h}$, subjects performed the Trier Social Stress Test (TSST), followed by mood and anxiety ratings. E2-treated subjects exhibited a significant increase in negative mood and anxiety after the TSST compared to placebo-treated women. These effects were independent of monoamine depletion and were not manifest before the TSST or at baseline. Exogenous estrogen administration in PMW may alter or modulate emotional reactivity to stressful events and may alter the sensitivity of emotional regulation. This modulation appears to be independent of alterations in monoaminergic neurotransmission. The dose of estrogen used after menopause may be important in determining the effects of gonadal steroids on emotional regulation. Neuropsychopharmacology (2008) 33, I5 I4-1527; doi:I0.I038/sj.npp. I301530; published online I5 August 2007
\end{abstract}

Keywords: estrogen; menopause; monoamines; stress; mood

\section{INTRODUCTION}

One of the strongest and most replicated epidemiologic findings in psychiatry is that there is a higher incidence of affective disorders in women with rates above puberty and below menopause approximately twice that of men (Kessler et al, 1994). This difference appears to equalize or reverse after age 55 years (Bebbington et al, 1998). After menopause, the rate of depressive illness in women relative to men declines and becomes more equal (Weissman and Myers, 1993). While many investigators have studied

A partial version of this work was previously presented as a poster at the American College of Neuropsychopharmacology Annual Meeting, San Juan, Puerto Rico, December 8-12, 2002.

*Correspondence: Dr PA Newhouse, Clinical Neuroscience Research Unit, Department of Psychiatry, University of Vermont College of Medicine, I South Prospect St, Burlington, VT 0540 I, USA, Tel: + I 802847 4560, Fax: + I 8028477889 ,

E-mail: paul.newhouse@uvm.edu

Received 30 March 2007; revised I 4 July 2007; accepted I 6 July 2007 potential reasons for this difference, the exact explanation or explanations remain unknown. While it is likely that the underlying causes are undoubtedly multifactorial, there is a general consensus among investigators that biological factors play a significant role. Among the strongest candidates for an important role in this gender difference are the gonadal steroids, chiefly $17 \beta$-estradiol (E2).

The effects of estrogen on mood appear to be complex and vary according to reproductive life stage. Increased vulnerability for depression in women appears to begin with puberty and declines after the menopause (Soares et al, 2003a; Steiner et al, 2003). While there has been controversy as to whether the risk of depression increases during the perimenopause, recent carefully controlled studies have suggested that the perimenopause is associated with increased vulnerability for both depressive symptoms and a diagnosis of new onset depression (Cohen et al, 2006; Freeman et al, 2006) even among women with no prior history of affective disorders. While the reasons for the increased female vulnerability to mood disorders remain to 
be fully understood, the strongest candidate remains the influence of cycling levels of gonadal steroids on neurotransmitter systems and mood regulatory systems (Steiner et al, 2003), perhaps interacting with genetic vulnerability and life stress (Caspi et al, 2003). The finding that previously asymptomatic women demonstrated increased risk for depression during the perimenopause suggests that perimenopausal associated instability in previously stable ovarian hormonal cycling (Prior, 1998) can induce mood instability even in women with few risk factors.

One possible hypothesis for the higher risk of affective disorders in pre- or perimenopausal women is that the monthly menstrual cycle, with its rising and falling E2 levels, produces instability in central monoaminergic neurotransmitter function (Steiner et al, 2003).

Estrogen levels vary widely during the perimenopause and postmenopause and this variability is associated with symptomatology, particularly vasomotor (Prior, 1998). After menopause, estrogen levels become lower but more stable concomitant with a decreased risk of depression. E2 and/or its loss have been shown to have significant effects on dopaminergic and serotonergic systems including modulation of 5-HT and DA receptor density (Fink et al, 1996), dopamine release (McDermott et al, 1994), potentiating serotonin function (Bethea et al, 2003; McEwen, 2002; Rubinow et al, 1993). Halbreich et al (1995) have shown that E2 administration augments the prolactin and cortisol response to the serotonin agonist $\mathrm{m}$-chlorphenylpiperazine in postmenopausal women (PMW). Administration of estrogen to PMW for several weeks has also been found to increase cortical serotonin-2A receptors (Kugaya et al, 2003). PMW taking estrogen have improved clinical responses to serotoninergic antidepressants (Nagata et al, 2005; Rasgon et al, 2007; Schneider et al, 1993; Soares et al, 2003b).

Fluctuations in estrogen levels may lead to alterations in levels of monoamine neurotransmitters, which may influence mood reactivity to external events. Therefore, this study examined whether estrogen administration in PMW can alter the mood response to changes in brain chemistry brought about using the acute amino-acid depletion technique added to the effects of experimentally induced psychosocial stress. The primary goal of this project was to test whether short-term administration of E2 to normal PMW, not on hormone therapy (HT), would alter mood reactivity to experimental psychosocial stress and quantitatively change the behavioral responses to CNS catecholamine and/or serotonin depletion, pharmacological challenges that directly interact with central monoamine systems. Acute tryptophan depletion (ATD) is a wellestablished technique for examining the role of serotonin systems in mood (Delgado, 2006; Young et al, 1993). Acute phenylalanine/tyrosine depletion (APTD) is a newer technique designed to examine the effects of reduced catecholamine synthesis and transmission on behavior and performance (Leyton et al, 1999). Tryptophan depletion can, in some circumstances, produce adverse effects on mood and behavior that are considered relevant to understanding the causes of affective illness (Delgado, 2006; Young and Leyton, 1993). Further, central catecholamine depletion has been examined in normal premenopausal women and has been found to produce negative effects on mood under stress (Leyton et al, 1999). Amin et al (2006b) have recently shown that E2 exerted a small positive mood effect on the day after ATD.

Prior studies of the effects of hormone treatment in PMW on experimentally induced psychological or psychosocial stress have generally focused on physiological reactivity such as blood pressure and hormonal responses (Burleson et al, 1998; Ceresini et al, 2000; Komesaroff et al, 1999; Kudielka et al, 1999; Lindheim et al, 1992b; Matthews et al, 2005). However, there has not been an experimental study that has focused on the effects of estrogen treatment in PMW on mood reactivity to psychosocial stress and examining whether hormonal effects interact with levels of brain monoamine neurotransmitters.

In this study, women who were postmenopausal $(>50$ years) took a fixed dose of E2 or placebo for 3 months. At the end of that time, they participated in three challenges using monoamine depletion to briefly change the relative amounts of neurotransmitters in the brain believed to be related to mood regulation (serotonin, dopamine, and norepinephrine). Subjects then participated in a mild psychosocial stress paradigm to potentiate negative mood (Trier Social Stress Test, TSST) (Kirschbaum et al, 1993). We hypothesized that the psychosocial stress manipulation (TSST) would enhance any negative mood effects of monoamine depletion and that estrogen administration would blunt or buffer potential negative mood effects produced by the combination of the monoamine depletion and the stress test in a measurable and quantifiable way. Since estrogen has been noted to interact with both serotonergic and catecholaminergic systems, it was hypothesized that depletion of either monoamine system might interact with estrogen treatment.

\section{METHODS}

The basic design consisted of a double-blind parallel group design (each subject was randomly assigned to receive either 3 months of E2 or placebo), with each treatment group then undergoing acute depletion and social stress challenges. All subjects signed fully informed consent after an explanation of all procedures, risks, and benefits. Subjects received $\$ 100$ as compensation for their time and a small gift pack after each study session. The study was approved by the University of Vermont Committee for Human Research in the Medical Sciences (IRB).

\section{Subjects}

Subjects were recruited through newspaper advertisement and health newsletters published by our Medical Center, public information sessions, newspaper advertisements, and random mailings. Study participants were first screened by phone for eligibility. Subjects consisted of 15 postmenopausal women (PMW) (52-83 years; mean age 67.1 \pm 11.2 years). Subject demographics are described in Table 1.

\section{Medical Screening}

Subjects were without menses for at least 1 year, had an FSH level greater than $30 \mathrm{mIU} / \mathrm{ml}$, nonsmokers, had a normal mammogram within the last year, and were without 
Table I Subject Demographic Data $(n=15)$

\begin{tabular}{lccc}
\hline & Mean \pm SD & Minimum & Maximum \\
\hline Estrogen treatment $(n=8)$ & & & \\
Age (years) & $68.13 \pm 12.63$ & 52.0 & 83.0 \\
Body mass index & $25.61 \pm 4.26$ & $18.7 \mid$ & 31.3 \\
Years since menopause & $16.91 \pm 12.51$ & 1.0 & 31.0 \\
Baseline FSH & $58.37 \pm 13.19$ & 42.8 & 73.4 \\
Education (years) & $14.63 \pm 2.83$ & 9.0 & 18.0 \\
& & & \\
Placebo treatment ( $n=7)$ & & & \\
Age (years) & $66.0 \pm 10.2$ & 55.0 & 80.0 \\
Body mass index & $25.93 \pm 4.38$ & 20.44 & 33.27 \\
Years since menopause & $15.97 \pm 11.51$ & 1.3 & 37.0 \\
Baseline FSH & $61.67 \pm 18.13$ & 38.6 & 86.3 \\
Education (years) & $15.57 \pm 2.82$ & 12.0 & 20.0 \\
\hline
\end{tabular}

surgically induced menopause (bilateral oophorectomy). They were not taking HT, or oral contraceptives, and were at least one year without such treatment. Subjects were physically healthy, had a body mass index $\leqslant 30 \mathrm{~kg} / \mathrm{m}^{2}$, and had no cardiovascular disease other than mild hypertension. Subjects with major concomitant illnesses were excluded on the basis of history, physical exam, and laboratory tests assessing hematopoietic, renal, hepatic, and hormonal function (CBC, Chem 20, TSH, U/A, ECG). Subjects were physically examined by a gynecologic nursepractitioner to establish general physical health and for specific physical contraindications for E2 therapy (eg adnexal mass, large uterine fibroids, etc.).

Subjects were excluded if they had specific contraindications for E2 treatment, or current or any past Axis I psychiatric disorders. Specific criteria for exclusion for the E2 treatment included contraindications for hormone replacement including history of breast cancer or E2dependent neoplasia; blood pressure $>160 / 100$ (untreated); history of deep vein thrombosis or other thromboembolic disease; hepatoma; severe migraines or stroke on oral contraceptives; concurrent use of barbiturates, rifampin, insulin, carbamezepine, oral hypoglycemics, antidepressants, or lipid-lowering drugs; known intolerance to conjugated E2s; diabetes; untreated thyroid disease; clinical osteoporosis; severe menopausal symptoms. All subjects were taking no centrally active drugs. No subjects were taking selective estrogen receptor modulators (SERMs) or herbal menopause preparations. A minimum of 14 days elapsed between discontinuing centrally active or psychoactive agents and any of these studies.

\section{Cognitive/Behavioral Screening}

All subjects were cognitively and behaviorally assessed using standard tests designed to exclude subjects with significant cognitive or behavioral impairment. Subjects were evaluated using the Mini Mental State Exam (MMS) (Folstein et al, 1975), Brief Cognitive Rating Scale (Reisberg and Ferris, 1988), the Mattis Dementia Rating Scale (Jurica et al, 2001) to establish a Global Deterioration Scale score
(GDS) which rates the degree of cognitive impairment (Reisberg et al, 1993a). Subjects were required to have a GDS score of 1-2 and an MMS score of greater than or equal to 27. Subjects were excluded if they scored below 123 on the Mattis scale and were matched as closely as possible across the two groups in terms of educational background. Behavioral screening consisted of a partial Structured Clinical Interview for DSM-IV-TR (SCID) (First et al, 2001) to establish the presence/absence of present or past Axis I major psychiatric disorders, particularly any present or past history of mood disorders. In addition, subjects completed the Beck Depression Rating Scale (Beck et al, 1961) and a menopause symptom checklist modified from Sherwin (1991) to detect subclinical depressive symptoms. An exclusion cutoff score of 10 was used for the Beck Depression Rating Scale.

\section{Estrogen/Placebo Treatment}

After screening and acceptance into the study, each subject was placed randomly and blindly on either oral placebo or E2 for 3 months. There were eight women in the E2 group and seven women in the placebo group. Women were initially placed on E2 $1 \mathrm{mg}$ /day for 30 days, and then were increased to $2 \mathrm{mg}$ /day. This was done because early pilot trials revealed that typical estrogen-related side effects (eg breast tenderness or spotting) tended to be troublesome if a subject was begun on $2 \mathrm{mg}$ of $\mathrm{E} 2$ from the beginning. Using $1 \mathrm{mg}$ of E2 for the first 30 days minimized these problems. At the end of the 3-month treatment period, subjects participated in a series of challenge studies designed to examine differences in sensitivity to acute transmitter depletion and psychosocial stress. E2 or placebo treatment continued throughout the challenge/stress studies. Twelve days of medroxyprogesterone acetate (MPA) (Provera) was given at the end of the study to produce shedding of the endometrial lining.

\section{Acute Depletion Challenges}

All studies took place on the University of Vermont General Clinical Research Center (GCRC). Each participant underwent 3 test days, at least 7 days apart, in which they received the each of the two amino-acid depletion mixtures and the nutritionally balanced control mixture. The depletion sequence was determined by a random order procedure.

The procedure for the administration of the amino-acid mixtures was the same as we have used previously (Leyton et al, 1999). Subjects were placed on a low-protein diet for the evening meal prior to each study day. Following an overnight fast, the study began at 0800 hours with baseline testing and evaluation. Subjects then ingested one of three amino-acid mixtures: (1) a nutritionally balanced aminoacid mixture, (2) a mixture deficient in tryptophan (ATD), or (3) a mixture deficient in phenylalanine and tyrosine (APTD). The composition of the amino-acid mixtures was that used in prior studies, adjusted for the generally lower weight of women. Mixtures consisted of amino acid suspended and water, with the worst tasting amino acids (L-motioning, L-cytokine, and L-argentine) in capsules. The liquid suspensions were flavored with noncaloric, noprotein flavoring of orange, grapefruit, lemon, chocolate, 
or cranberry-lemon (subject's choice) to disguise the unpleasant taste. We have previously demonstrated the feasibility of administering three amino-acid mixtures to female subjects with acceptable tolerability (Ellenbogen et al, 1996). Testing concluded with a high protein snack for repletion of amino-acid levels.

\section{Social Stress Test}

At $5 \mathrm{~h}$ after amino-acid ingestion, subjects performed a mildly stressful psychological task, the TSST (Kirschbaum et al, 1993). The TSST consisted of three parts, a brief Instruction Period, a 10-min Anticipation Period, and a 10min Test Period. For the brief Instruction Period, subjects were taken to the TSST room where three persons were already sitting at a table and a visible video camera was set up. The subject was asked to stand on an ' $X$ ' on the floor in front of the panel of people. The Instructor presented the subject with one of three scenarios and asked the subject to prepare a 5-min speech about the topic. Subjects were told that the panel was specially trained to monitor nonverbal behavior and that a voice-frequency analysis of the speech would be performed. Following the instructions, the subject returned to her room.

During the Anticipation Period, subjects were asked to prepare the 5 -min speech. They were given $10 \mathrm{~min}$ to prepare and take notes in a separate room, but were not allowed to use them during their speech. Subjects presented their 5-min speech followed by $5 \mathrm{~min}$ of arithmetic problems. The TSST was originally designed to be conducted one time per subject, utilizing only the first speech scenario and arithmetic problem. In order to repeatedly confront the subject with the TSST on each of the three study visit days, the two additional scenarios and arithmetic problems were created. For each of the three scenarios, the subject was asked to take on a role within a given context and had to convince a panel to grant her a specific request: (1) role of a job applicant for the position of manager at a banking firm. (2) Role of the director of a rehabilitation program for prisoners requesting a donation of a large sum of money to support the program. (3) Role of a building developer requesting a building permit to build a strip mall in a rural New England town. For the arithmetic problem portion of the Test Period, the problems consisted of serial subtractions of a two digit number from a four digit number, and upon every mistake, the subject was asked to begin again at the first number.

Repeated exposure to the TSST has been shown to induce an equal physiologic stress response (Kirschbaum et al, 1995; Rohleder et al, 2001). Consultation with the creators of the TSST and their review of our scenarios produced general agreement that the repeated use of the TSST with our scenarios had precedent and would produce repeated equivalent stress (NC Schommer, personal communication).

Subjects were briefed before the study began about the general nature of the TSST and what was expected of them. This was done so as to equalize the anticipation of the TSST across the three study days. It should be noted that the actual performance of the subject during the TSST was not evaluated. The psychological stress induced was a product of the actual event of standing in front of a panel of strangers and delivering a speech; thus, the topic of the speech was less important. Regardless, the speech scenarios and arithmetic problems were judged to be equal in difficulty and equivalently controversial topics for the population being studied. Further, the order of scenarios was randomized across subjects, decreasing the possibility that differences in scenarios would produce different stress outcomes. Subjects were debriefed at the end of the study regarding the mild deception in the stress test (ie, no actual monitoring of test performance).

\section{Outcome Measures}

Behavior. The primary outcome mood and anxiety measure was the subject-completed Profile of Mood States (POMS) (McNair et al, 1971). This scale is a 65-item adjective checklist that generates six bipolar factor-analytically derived factors, (elated-depressed, composed-anxious, energetic-tired, agreeable-hostile, confident-unsure, and clearheaded-confused) or 12 unipolar factors, plus total score. This scale has been used extensively in challenge study paradigms and is sensitive to the effects of psychotropic drugs and CNS state manipulations. It was administered three times during the experimental session: pre-depletion, post-depletion prior to TSST, and post TSST. Subjects completed a Beck Depression Index (BDI) (Beck et al, 1961) twice during the day: pre-depletion and post-depletion but prior to the TSST. Subjects also completed a Visual Analog Battery four times during the experimental day: predepletion, post-depletion prior to TSST, post TSST, and $1 \mathrm{~h}$ later at the end of the study. Each rating item in the battery was scored on a $100 \mathrm{~mm}$ line and included items rating anxiety, mood, alertness, physical comfort, fear, irritability, hunger, and sense of interest.

Observer ratings consisted of the Brief Psychiatric Rating Scale (Overall and Gorham, 1993) that was scored at the end of the day, and a Visual Analog Battery including ratings of drowsiness, motoric restlessness, disorientation, impaired speech, euphoria, irritability, sweating, GI distress, motor incoordination, fatigue, depression, anxiety, and alertness, all scored on a $100 \mathrm{~mm}$ line. This was scored four times per session: pre-depletion, post-depletion prior to TSST, post TSST, and end of study day.

Neuroendocrine/physiologic. Measures of E2 and FSH were collected to assess compliance and the effectiveness of E2 therapy. E2 and FSH were measured with an ADVIA Centaur chemiluminescence competitive immunoassay (E2) and an ADVIA Centaur two-site sandwich immunoassay (FSH), both utilizing a labeled acridinium ester. Samples were collected at screening and on the first day of each challenge sequence. Blood was collected on each study day for measures of plasma total tryptophan, phenylalanine, and tyrosine to assess the adequacy of depletion. Samples were collected pre-depletion $(-45 \mathrm{~min})$ and end of session ( + $400 \mathrm{~min})$. Plasma phenylalanine and tyrosine concentrations were determined using a Beckman System Gold amino-acid analyzer using gradient HPLC with precolumn derivatization and fluorometric detection. Tryptophan was measured by isocratic HPLC with fluorometric detection. Cortisol was measured by radioimmunoassay (Diagnostic Products Corporation). 
Vital signs were recorded pre-depletion at $-45 \mathrm{~min}$, preTSST at $+300 \mathrm{~min}$, and post-TSST at $+400 \mathrm{~min}$. A cognitive battery was also administered following the completion of mood ratings. This battery consisted of tests of attention, learning, and memory and will be reported separately.

\section{Data Analysis}

The general approach was that of mixed model repeated measures analysis of variance (ANOVA) utilizing SAS PROC MIXED. Initial analysis of behavioral measures was a $2 \times 3 \times 3$ treatment (2) $\times$ depletion (3) $\times$ time-point (3) mixed model ANOVA as an overall test of the effect of E2 treatment on monoamine depletion effects and reactivity to psychosocial stress. Treatment (E2 vs placebo) was the between-subjects factor and depletion (ATD, APTD, and mock) and time were the within-subject factors. For the time factor, the time points used in the overall ANOVA were pre-depletion, post-depletion but directly before the TSST, and after the TSST. As the primary effect of interest was the impact of E2 treatment on reactivity to monoamine depletion and psychosocial stress, if no treatmentby-depletion effect was found, results were collapsed across depletions and the analyses were redone as a $2 \times 3$ (treatment $\times$ time) ANOVA. When there was a significant interaction (eg, treatment $\times$ time), non-orthogonal a priori contrasts were used to test for differences between treatment across time. The $\alpha$ level for rejection of the null hypothesis was set at $p<0.05$.

\section{RESULTS}

\section{Subjects}

Subjects were matched for age, education, weight, and years since menopause (Table 1). The mean age of subjects was $67.1 \pm 11.2$ years. BMI averaged $25.8 \pm 4.2 \mathrm{~kg} / \mathrm{m}^{2}$ and subjects were on average of $16.4 \pm 11.7$ years postmenopause. This was a highly educated group with an average of 15.1 years of education. Nine subjects had previous experience with hormone replacement therapy ( $>1$ year previously) and six did not. For those women who had previously used HT, the average duration of hormone use was $2.0 \pm 3.4$ years with an average of $10.2 \pm 11.0$ years since hormone use prior to study participation. Average screening FSH level was 59.8.

\section{FSH and E2 Levels}

Pretreatment FSH showed a mean level of $59.8 \mathrm{mIU} / \mathrm{ml}$ (menopausal level is considered above $30-35 \mathrm{mIU} / \mathrm{ml}$ ) and was not significantly different between treatment groups $(\mathrm{t}(13)=0.69, p=0.4)$. After 3 months of treatment, the E2-treated subjects showed a significantly reduced mean FSH level of 26.3 compared to the placebo-treated subjects who had a mean level of 63.1 $(\mathrm{t}(13)=4.6, p=0.0005)$. Mean plasma E2 levels after 3 months of treatment were significantly elevated at $146.13 \mathrm{pg} / \mathrm{ml}$ for the E2-treated group compared to $16.6 \mathrm{pg} / \mathrm{ml}$ for the placebo-treated group $(\mathrm{t}(13)=4.58, p=0.0005)$. The levels of E2 seen in the E2treated women are comparable to late follicular phase levels in premenopausal women, whereas the level seen in the placebotreated women is comparable to the early follicular phase.

\section{Amino-Acid Levels}

Plasma concentrations of total tryptophan, phenylalanine, and tyrosine were measured at baseline (pre-depletion) and at $+400 \mathrm{~min}$ (post-depletion) (Table 2). After tryptophan depletion, plasma tryptophan levels declined $84 \%$. After tyrosine/phenylalanine depletion, tyrosine levels declined $76 \%$ and phenylalanine levels declined $68 \%$, suggesting that an adequate depletion was achieved (Golightly et al, 2001; Leyton et al, 1999).

\section{Clinical Assessment of Mood across Treatment Phase}

A comparison of the clinical depression ratings (BDI) from screening to the end of the treatment phase for each subject revealed no significant time-by-treatment interaction $(\mathrm{F}(1,13)=0.08, p=0.78)$. Furthermore, a comparison of the end of treatment BDI scores (the baseline BDI score on the first depletion challenge day) between treatment groups showed a small numerical difference (PLC: $1.6 \pm 3.3$; E2: $4.6 \pm 3.2)$ that was not significantly different between treatments $(\mathrm{t}(13)=1.8, p=0.09)$. These data demonstrate that the treatment alone (E2 or placebo) did not produce significant or clinically manifest negative changes in mood across the three-month treatment phase nor did the groups differ prior to beginning the monoamine depletion challenges.

\section{Experimental Mood Assessment}

Mood ratings, pre- and post-TSST are presented in Table 3. The primary self-rated mood assessment (POMS) was conducted three times during each experimental day, prior to depletion (daily baseline), post-depletion but prior to the TSST, and post-TSST. Initial three-way analyses

Table 2 Amino-Acid Levels $(n=15)$

\begin{tabular}{|c|c|c|c|}
\hline & $\begin{array}{l}\text { Pre-depletion } \\
\text { mean } \pm \text { SD }\end{array}$ & $\begin{array}{c}\text { Post-depletion } \\
\text { mean } \pm \text { SD }\end{array}$ & $\begin{array}{c}\text { Percent change } \\
\text { mean } \pm S D\end{array}$ \\
\hline \multicolumn{4}{|c|}{ Total plasma tryptophan ( $\mu$ mol/I) } \\
\hline ATD & $49.38 \pm 6.68$ & $7.89 \pm 2.72$ & $-84.30 \pm 4.01$ \\
\hline ATPD & $48.78 \pm 9.60$ & $64.80 \pm 20.29$ & $42.11 \pm 70.62$ \\
\hline MOCK & $47.68 \pm 8.09$ & $58.24 \pm 16.35$ & $28.22 \pm 53.24$ \\
\hline \multicolumn{4}{|c|}{ Plasma phenylalanine ( $\mu \mathrm{mol} / \mathrm{I})$} \\
\hline ATD & $50.97 \pm 15.6$ & $90.56 \pm 39.86$ & $78.84 \pm 67.12$ \\
\hline ATPD & $45.64 \pm 6.72$ & $14.48 \pm 4.45$ & $-67.73 \pm 11.37$ \\
\hline MOCK & $47.94 \pm 5.15$ & $74.60 \pm 36.77$ & $52.32 \pm 63.09$ \\
\hline \multicolumn{4}{|c|}{ Plasma tyrosine ( $\mu$ mol/l) } \\
\hline ATD & $63.64 \pm 27.89$ & $188.43 \pm 57.78$ & $215.07 \pm 91.46$ \\
\hline ATPD & $55.81 \pm 12.72$ & $13.89 \pm 4.00$ & $-75.19 \pm 3.65$ \\
\hline MOCK & $57.91 \pm 10.39$ & $184.18 \pm 54.87$ & $231.08 \pm 120.37$ \\
\hline
\end{tabular}

ATD: Acute Typtophan Depletion; ATPD: Acute Tyrosine/Phenylalanine Depletion; MOCK: Mock (Placebo) Depletion.

Pre-depletion time point is $-45 \mathrm{~min}$; depletion time point is $0 \mathrm{~min}$; postdepletion time point is $+420 \mathrm{~min}$. 
Table 3 Mood Ratings Data $(n=15)$

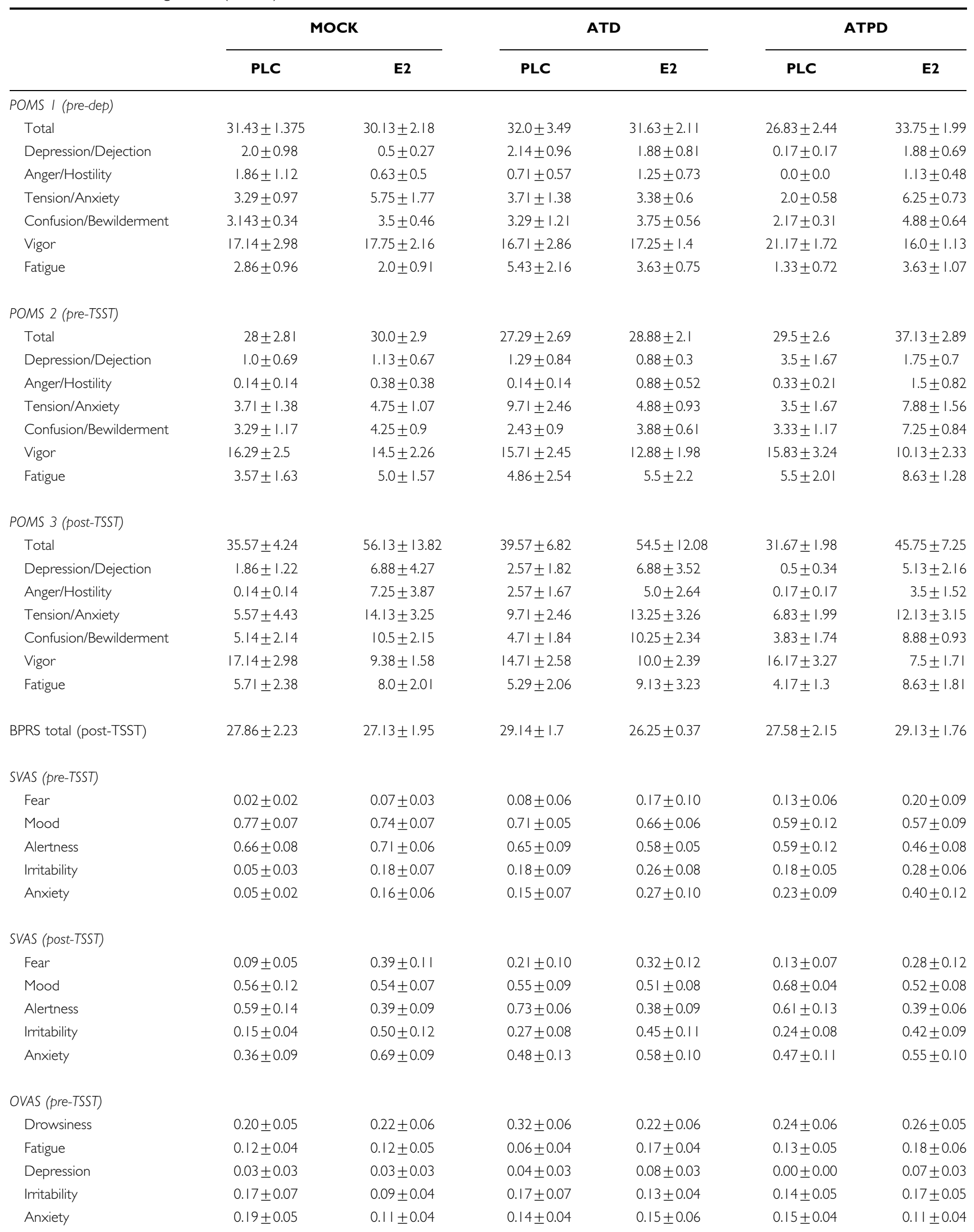


Table 3 Continued

\begin{tabular}{|c|c|c|c|c|c|c|}
\hline & \multicolumn{2}{|c|}{ MOCK } & \multicolumn{2}{|c|}{ ATD } & \multicolumn{2}{|c|}{ ATPD } \\
\hline & PLC & E2 & PLC & E2 & PLC & E2 \\
\hline Drowsiness & $0.14 \pm 0.03$ & $0.09 \pm 0.04$ & $0.16 \pm 0.07$ & $0.21 \pm 0.07$ & $0.13 \pm 0.04$ & $0.20 \pm 0.05$ \\
\hline Fatigue & $0.10 \pm 0.05$ & $0.15 \pm 0.04$ & $0.10 \pm 0.08$ & $0.26 \pm 0.06$ & $0.05 \pm 0.03$ & $0.19 \pm 0.06$ \\
\hline Anxiety & $0.34 \pm 0.08$ & $0.27 \pm 0.07$ & $0.34 \pm 0.06$ & $0.19 \pm 0.04$ & $0.31 \pm 0.06$ & $0.24 \pm 0.08$ \\
\hline
\end{tabular}

(treatment $\times$ challenge $\times$ time) showed no significant or trend-level treatment-by-challenge interactions. Thus, for the analysis of hormone treatment effects (the primary experimental manipulation of interest), the results were pooled across challenge (see below) rather than examining each depletion challenge individually (against the mock depletion) by treatment. There were two challenge-by-time interactions: POMS total $(\mathrm{F}(4,13)=10.54, p=0.0005)$ and Fatigue factor $(\mathrm{F}(4,13)=3.93, p=0.04)$. However, no post hoc comparisons of interest were significant for the POMS total score. For the Fatigue factor, APTD increased scores significantly $(\mathrm{t}(13)=2.6, p=0.02)$ for the pre-TSST time point.

POMS Total Score showed a significant treatment-by-time interaction $(\mathrm{F}(2,13)=5.18, p=0.02)$, with the total score being substantially and significantly $(p=0.025)$ increased post-TSST in the E2-treated group compared to the placebo-treated group (Figure 1). The magnitude of the increase after the TSST in POMS total score after the TSST was nearly three times as large in the E2-treated group (20.13) compared to the placebo group (7.6).

Virtually all POMS factors (Figure 1) showed significant treatment-by-time interactions or main effects of treatment with the E2-treated group showing significant changes in ratings of negative mood and related effects after the TSST (Table 3). The Tension-Anxiety factor showed a main effect of E2 treatment $(\mathrm{F}(1,13)=9.59, p=0.01)$. Examining preand post-TSST time points showed a large main effect of E2 $(p<0.001)$ and no interaction with challenge. The Depression factor showed a significant $(\mathrm{F}(2,26)=5.29, p=0.01)$ time-by-treatment interaction with subjects treated with E2 showing significantly greater depression $(\mathrm{t}(26)=2.48$, $p=0.02$ ) post TSST then subjects treated with placebo. Similar time-by-treatment interactions occurred for the Vigor factor $(\mathrm{F}(2,26)=38.11, p<0.0001)$ and the Confusion/Bewilderment factor $(\mathrm{F}(2,26)=23.5, p<0.0001)$. For the Confusion/Bewilderment factor, post hoc comparisons showed that the E2-treated group had significantly $(\mathrm{t}(13)=8.20, p<0.0001)$ greater negative response after the TSST compared to the placebo-treated group. In the case of the Vigor factor, the E2-treated group showed a significant $(\mathrm{t}(13)=4.73, p=0.001)$ greater decline postTSST. For the Anger/Hostility factor, there was a main effect of E2 treatment $(\mathrm{F}(1,13)=4.48, p=0.05)$ with $\mathrm{E} 2$ treatment being associated with greater self-ratings of anger and hostility. The Fatigue factor showed a significant $(\mathrm{F}(2,13)=5.67, p=0.02)$ time-by-treatment interaction. Post hoc comparisons showed that the E2-treated group reported significantly $(\mathrm{t}(13)=4.73, p=0.0004)$ greater fatigue than the placebo-treated group.

Additionally, as a secondary method of assessing whether the effects of E2 on emotional reactivity were not dependent on monoamine depletion, we examined the effects of E2 treatment during the mock depletion (nutritionally balanced amino-acid administration) condition separately. Two POMS factors showed significant time-by-treatment interactions: depression $(\mathrm{F}(2,13)=5.54, p=0.02)$ and Vigor $(\mathrm{F}(2,13)=4.08, p=0.04)$. The Anger/Hostility factor showed a trend toward an interaction $(\mathrm{F}(2,13)=3.46$, $p=0.06)$. The Tension/Anxiety factor showed a significant $(\mathrm{F}(1,13)=6.42, p=0.02)$ treatment effect with a larger negative effect of E2 and the Confusion factor showed a trend in the same direction $(p=0.10)$. These results support the finding that the increase in emotional reactivity after the TSST was determined in large part by the presence of E2.

In the entire model (treatment $\times$ depletion $\times$ time) and the pooled model, no change in the results was seen after including age as a covariate. Furthermore, as the correlation in our sample between age and time since last menstrual period (LMP) was very high at $r=0.95$, time since LMP similarly would not influence the results. Neither day nor TSST scenario interacted with hormone treatment or depletion challenge. We also examined the effect of repeated administration of the TSST and the impact of the three different TSST scenarios on the POMS total score and although small effects were seen on challenge day and scenario, no significant interaction with hormone treatment or depletion challenge was found. Depletion challenge, TSST scenario, and hormone treatment were completely randomized, thus minimizing any effects on results.

\section{Subject Visual Analog Scale Battery}

Subject visual analog scale battery (VAS) showed results consistent with that of the POMS. There were no significant treatment-by-challenge interactions, thus the subsequent analyses were pooled across challenges. The Fear VAS showed a significant time-by-treatment interaction $(\mathrm{F}(3,39)=5.58, p=0.003)$ as did the Irritability VAS $(\mathrm{F}(3,39)=7.41, p=0.0005)$ with $\mathrm{E} 2$-treated subjects rating themselves as having significantly greater fear $(\mathrm{t}(39)=2.44$, $p=0.02)$ and irritability $(\mathrm{t}(39)=2.69, p=0.01)$ following the TSST. Anxiety, mood, alertness, comfort, and hunger all showed expected significant time effects (all $p<0.01$ ) but no interactions with treatment. 

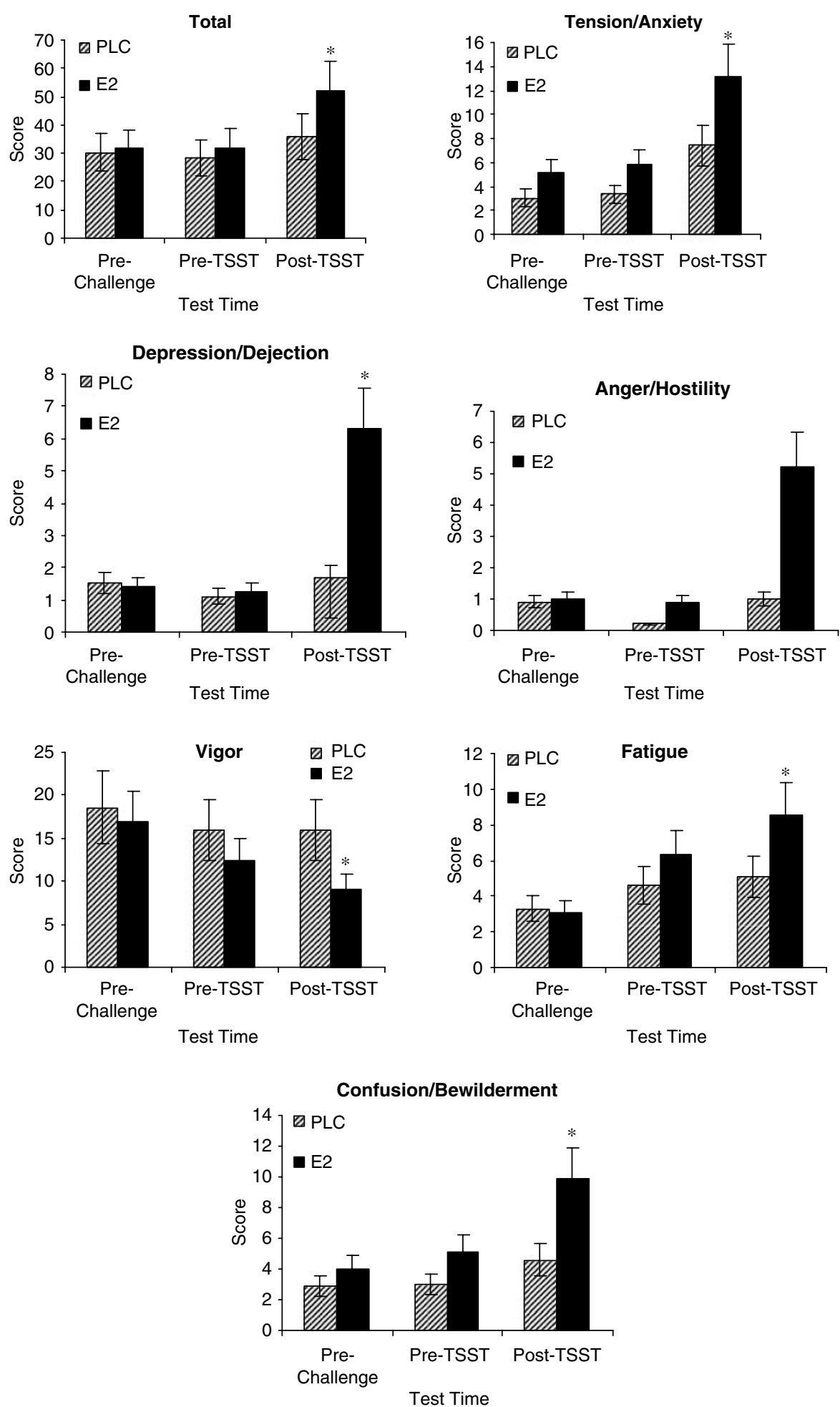

Figure I POMS Total and Factor Scores pre-depletion, immediately preceding (pre-TSST) and following (post-TSST) the TSST pooled across depletions. PLC: placebo; E2: estradiol. For the total and all factor scores, except Anger/Hostility, ANOVAs showed significant treatment-by-time interactions ( $p \leqslant 0.02$ ). Anger/Hostility showed a main effect of E2 treatment $(p=0.05)$. Values shown are adjusted mean scores \pm SEM. * $p<0.05$ E2 vs PLC.

\section{The Observer Visual Analog Battery}

Drowsiness showed a treatment-by-challenge-by-time (three-way) interaction $(\mathrm{F}(6,13)=10.35, p=0.0003)$. As there were no other treatment-by-challenge interactions, the remaining analyses were collapsed across challenges. There was a significant treatment-by-time interaction for the Anxiety VAS $(\mathrm{F}(3,39)=2.91, p=0.046)$, the Alertness VAS $(\mathrm{F}(3,13)=12.53, p=0.0004)$, and the Fatigue VAS $(\mathrm{F}(3,13)=19.53, p<0.0001)$. There was no difference in 
alertness ratings between the groups post-TSST $(\mathrm{t}(13)=1.0$, $p=0.34)$. For the Depression VAS, there was a trend for a treatment-by-time interaction $(\mathrm{F}(3,39)=2.5, p=0.07)$, but also a main effect of treatment $(\mathrm{F}(1,13)=7.3, p=0.02)$. Post hoc comparisons showed that immediately after the TSST, E2-treated subjects were rated as significantly more depressed $(\mathrm{t}(39)=2.92, p=0.006)$ than the placebo-treated subjects, but placebo-treated subjects were rated as being rated more anxious than E2-treated subjects $(\mathrm{t}(39)=2.19$, $p=0.03$ ). The magnitude of these differences was small. The 24-item BPRS was used by the blinded observer to rate mood and behavior after the TSST. An analysis of the BPRS total score and factor scores showed only trend level $(p<0.07)$ effects on the Hostility factor and the Impairment factor with E2-treated women showing somewhat greater impairment.

\section{Vital Signs and Neuroendocrine Measures}

Minor effects of amino-acid depletion were seen on systolic and diastolic blood pressure. Pulse showed a significant $(\mathrm{F}(1,13)=8.43, p=0.01)$ effect of $\mathrm{E} 2$ treatment, but no interactions with hormones or amino-acid depletion were found. Other vital signs such as temperature showed modest challenge- and stress-related changes as expected but did not show any significant E2 treatment-related effects or any systematic results of monoamine depletion. No clinically relevant changes occurred. Cortisol levels were also measured at baseline and $+420 \mathrm{~min}$ (post-TSST). Baseline levels (predepletion, pre-TSST) were significantly $(\mathrm{t}(43)=2.77, p=0.008)$ higher in the E2-treated subjects (Figure 2). Although cortisol levels declined across the experimental day under all three challenge conditions, levels declined significantly less $(\mathrm{F}(2,25)=3.65, p=0.04$ for challenge-by-time interaction) after ATD and APTD than after Mock depletion (Figure 2).

\section{DISCUSSION}

Post-menopausal women who were administered E2 at a dose of $1 \mathrm{mg}$ of oral E2/day for 1 month, then $2 \mathrm{mg} /$ day for 3 months exhibited a markedly exaggerated negative emotional response to a psychologically stressful event. This response was independent of the effects of monoamine depletion, which appeared to have only a small overall effect on the emotional responses and did not interact with the effects of E2. These effects did not appear to be secondary to baseline differences prior to depletion or the TSST, as subjects' end of treatment depression scores (Beck), and pre-depletion mood scores (POMS), and depression scales were not significantly different between treatment groups. The effects seen in this study were at variance from what might have been expected regarding the effects of E2 on the modulation of stress, that is, that E2 might reduce the effects of stressful events, due to salutary effects of E2 on the expression of monoamine neurotransmitters, such as 5-HT (Kugaya et al, 2003). We expected that monoamine depletion and psychosocial stress together would produce negative mood changes, as was seen by Leyton et al (1999) but that might be modified by the presence of E2. Monoamine depletion produced only minor negative mood changes compared to mock depletion. By comparison, the effects of E2 on mood reactivity to social stress were larger and appeared to be largely independent of the monoamine depletion maneuvers.

We elected to study PMW rather than perimenopausal women as our primary interest was in examining stress sensitivity in older women and the interaction with exogenously administered gonadal steroids. Including perimenopausal women (defined as those who had menses for at least one year) would have meant including women who were having occasional bleeding episodes, indicating that endogenous estrogen and progesterone are still being produced, thus making it difficult to know what the total hormonal exposure would be. Giving such subjects estrogen would cause increased irregular bleeding as the exogenously hormones would not necessarily suppress their pituitary. Studying perimenopausal women utilizing this model may be done in the context of a separate study.

To properly place these results within the context of prior research on estrogen and mood in older women, we discuss below prior work on monoamine depletion with psychosocial stress, studies of the effects of estrogen on the stress sensitivity of PMW, effects of varying estrogen levels on brain function, and estrogen effects on mood in normal and depressed PMW.

\section{Monoamine Depletion in Women}

The monoamine depletion maneuvers did not significantly interact with psychosocial stress to produce large changes in
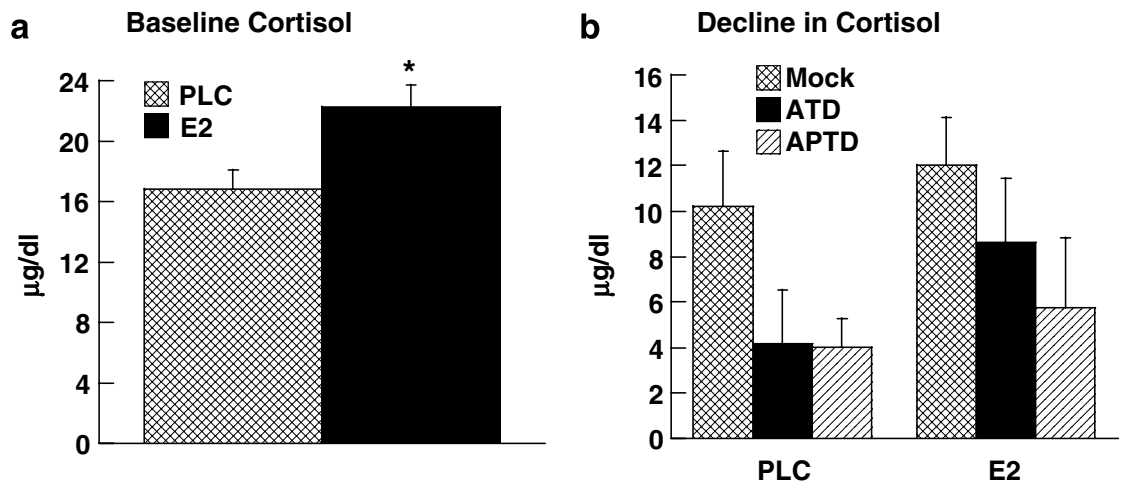

Figure 2 (a) Baseline cortisol levels measured at time point $-45 \mathrm{~min}$. (b) Decline in cortisol levels from baseline ( $-45 \mathrm{~min})$ to post-TSST ( $+420 \mathrm{~min}$ ); ( $p<0.05$ for challenge $\times$ time interaction). PLC: placebo; E2: estradiol; ATD: acute tryptophan depletion; ATPD: acute tyrosine/phenylalanine depletion; MOCK: mock (placebo) depletion. Values shown are mean scores \pm SEM. $* p<0.05$ E2 vs PLC. 
vigor, depression, tension/anxiety, confusion, anger/hostility, or total mood disturbance scores, even when participants were subjected to a psychosocial stressor. This is at variance with some but not all previous studies. Ellenbogen et al (1999) found a significant mood-lowering response after tryptophan depletion in normal women with no family history of psychiatric illness. Leyton et al (1999) also found a significant mood-lowering effects of both tryptophan and tyrosine/phenylalanine depletion in women after the same psychosocial stressor used in this study (TSST). Both of these studies examined premenopausal women in their 20 s. Ellenbogen and colleagues reported in a later study (1999) that they were unable to find a mood-lowering effect of tryptophan depletion in a group of young women with a positive family history of affective disorders. Harrison et al (2004) showed alterations in cognitive performance after either ATD or ATPD compared to placebo in normal young women but no alterations were seen in mood state. Porter et al (2005) examined the response of 17 older PMW, 10 of whom were recovered from major depression, after ATD. No clinically significant mood effects were seen, even in this highly vulnerable group.

\section{Stress Sensitivity of PMW}

PMW appear to show greater sensitivity than premenopausal women in their physiologic response to cognitive and speech tasks with the difference being ascribed to both age and hormonal status (Saab et al, 1989). Previous studies of the effects of hormones on various forms of experimental stressors have found that the various forms of estrogen appear to reduce some of the physiologic effects of mild laboratory-induced stress (eg, solving arithmetic problems) (Ceresini et al, 2000). Lindheim et al (1992a) found that PMW showed greater biophysical reactivity following math and speech tasks compared to premenopausal women, but this was reduced after 6 weeks of transdermal E2 treatment. In a follow-up study, Lindheim et al (1994) found that the addition of medroxyprogesterone acetate (MPA) blunted the ability of transdermal E2 to reduce physiologic responses to mild stressors. Matthews et al (2005) reported that PMW treated with estrone and micronized progesterone showed diminished blood pressure responses to laboratory stressors compared to subjects treated with estrone alone, estrone plus methyltestosterone, or placebo. Burleson et al (1998) showed that women on either estrogen or estrogen plus a progestogen treatment showed enhanced parasympathetic responsiveness to experimental stress, suggesting reduced sympathetic activation. Komesaroff et al (1999) found that 8 weeks of E2 supplementation produce a similar reduction of physiological responses to mental stress. In a low dose, short duration transdermal estrogen study in PMW, the TSST was not found to provoke a differential effect on physiological measures in estrogentreated women (Kudielka et al, 1999). In an extensive review, Kajantie and Phillips (2006) conclude that there is an increase in sympathoadrenal responsiveness after menopause which is attenuated during oral hormone therapy and that sex differences in sympathoadrenal responses are likely the result of estrogen. Our E2-treated subjects had a significantly higher baseline cortisol level, but this is likely due to a direct effect of E2, which will elevate plasma total and free cortisol levels (Baumann, 1983). As cortisol levels normally decline across the day, we are interested in whether E2 treatment interacted with monoamine depletions to influence this decline. Monoamine depletion did cause a reduction in the decline of cortisol levels after the TSST, but did not interact with E2 treatment.

The results of the present study do not align with some of the prior human studies discussed above. The reasons may be multifactorial and may include the dose and duration of estrogen used in this study (discussed below) and the more intense nature of the stressor (amino-acid drinks plus psychosocial stressor over a period of $6 \mathrm{~h}$ ). It is also possible that the effects of estrogen treatment on reactivity to psychosocial stress after menopause may be nonlinear. For example, in animal models, higher levels of estrogen appear to interact with stressful experiences to produce behavioral dysfunction. Shansky et al (2004) showed that female rodents were impaired after a chemical and behavioral stressor if they were in high estrogen phases of the estrous cycle or if they were given estrogen replacement after ovariectomy. Wood and Shors (1998) demonstrated that stress-induced impairment in female rat conditioning is dependent on the presence of ovarian hormones as ovariectomized animals did not show stress-induced behavioral impairment.

\section{Estrogen Effects on Mood after Menopause}

Comparing the immediate pre-challenge BDI scores (after 3 months of E2 or placebo treatment), there was a trend $(p<0.1)$ for the E2-treated subjects to rate themselves slightly higher, that is higher depression scores (although still very low scores). However, we found no hint of a treatment-by-time interaction $(p=0.8)$ in BDI scores across the treatment phase of this study, strongly suggesting that estrogen treatment did not influence baseline depression scores prior to the depletion and stressor maneuvers. Experimental studies that have examined the effects of estrogen and related compounds on mood after menopause have produced conflicting results. Studies have found positive effects on mood (Best et al, 1992; Miller et al, 2002), no effects (Cummings and Brizendine, 2002; Schleifer et al, 2002), and dose-related negative effects (Björn et al, 2003; Sherwin, 1991). Earlier large observational studies (Palinkas and Barrett-Connor, 1992; Whooley et al, 2000; Zweifel and O'Brien, 1997) suggested an overall positive effect size for estrogen therapy in improving depressed mood in menopausal women. However, interventional studies such as the HERS study (Hlatky et al, 2002) and the Women's Health Initiative (WHI) trial (Hays et al, 2003) found no significant benefits on mood or quality-of-life outcomes except in women with severe vasomotor and sleep symptoms. Recently, in the Women's Health Initiative Study of Cognitive Aging (WHISCA) (Resnick et al, 2006) a small increase in negative affect was seen, and in the Euralox trial, women on estrogen or combined treatment reported greater deterioration in scores for depressed mood (Voss et al, 2002).

Studies of estrogen supplementation for the treatment of postmenopausal depression have produced positive (Rasgon et al, 2002, 2007; Schmidt et al, 2000) as well as neutral 
or negative (Goldstein et al, 2005b; Morrison et al, 2004) results. Whether primary mood effects in depressed PMW can be separated from secondary improvement and mood due to improvement and vasomotor symptoms is unclear (Stoppe and Doren, 2002). Women with low E2 levels may be more likely to have a positive mood response to estrogen treatment for depression (Grigoriadis and Kennedy, 2002). Our subjects were chosen particularly for having no current or prior history of depression, thus if mood effects of estrogen follow an upside down ' $U$ '-shaped function (subjects with impaired mood experiencing benefit and subjects with normal mood experiencing no benefit or negative effects), then the negative effects of estrogen treatment following psychosocial stress become more plausible.

\section{Is the Dose of the E2 or Age Important in Explaining these Results?}

The dose of E2 and the subsequent plasma level of E2 that subjects experienced in this study may play an important role in explaining why an exaggerated negative response to psychosocial stress was seen in this study. Alterations in the level of naturally cycling gonadal steroids appear to produce significant alterations in the cortical processing of emotional stimuli. Pearson and Lewis (2005) demonstrated that women during high estrogen phases of the menstrual cycle were more accurate at assessing fearful facial expressions than low estrogen phases. Recent functional neuroimaging studies in premenopausal women have demonstrated significant differences in cortical activation of emotional stimuli-modulating areas in response to positive and negative emotional stimuli during high- $v s$ low-estrogen periods of the menstrual cycle (Amin et al, 2006a; Goldstein et al, 2005a; Protopopescu et al, 2005). Alterations in cortical activity produced by differing circulating levels of hormones such as E2 may play a role in regulating how the amygdala and other emotion-related structures respond to emotional stimuli and/or stressful events. Alterations in stress responsivity may occur across the normal menstrual cycle (eg, periovulatory) and may be linked to elevated E2 levels and/or interactions with $\mathrm{CRH}$ and other parts of the HPA axis (Magiakou et al, 1997). How the processing of emotional stimuli changes after menopause is at this point unknown. Thus, it may be that the steady administration of E2 to PMW at a plasma level consistent with late follicular phase, as in this study, may have produced alterations in the cortical or subcortical processing of stressful or emotional experiences. While we did not take E2 levels on each depletion challenge day, the challenges were randomized thus mitigating any possible effects of day-to-day variations in E2 levels. Compliance with E2/PLC treatment was excellent and thus we think it unlikely that plasma levels would vary significantly within subjects. While parametric imaging studies have not been conducted in PMW, such studies may be useful to parse the effects of E2 $v s$ other hormones such as progesterone and whether the processing of stressful or emotional stimuli changes in the female brain once the influence of cycling levels of gonadal steroids are no longer present.

Neither age nor time since LMP significantly altered the results. Nine of our subjects did have prior exposure to hormone therapy, with an average of 10 years since last exposure. These nine subjects were evenly distributed between the two treatment groups (four and five in the placebo and E2 groups, respectively), thus the effects of this difference are unlikely to have had a significant effect on the results.

\section{Potential Mechanisms}

While the exact neurochemical mechanisms responsible for the exaggerated emotional responses seen here cannot be ascertained from this particular study, the lack of interaction of the E2-induced effect on stress reactivity with monoamine depletion suggests that other neurotransmitter systems may be involved in mediating these effects. Estrogen administration appears to increase CRH mRNA in female rhesus monkeys who had undergone ovariectomy (Roy et al, 1999), and appears to be able to directly regulate human $\mathrm{CRH}$ gene expression (Vamvakopoulos and Chrousos, 1993) and regulate HPA axis activity in response to stress (Carey et al, 1995), indicating ovarian steroid regulation of stress-induced neuroendocrine responses. There is also evidence that sex steroid hormones influence $\mathrm{GABA}_{\mathrm{A}}$ receptor activity through allosteric modulation (Beyenburg et al, 2001). Progesterone levels and associated steroid derivatives appear to decline precipitously after menopause, with levels falling to less than $30 \%$ of premenopausal levels (Goldfien and Monroe, 1983). Decline in progesterone and their neurosteroids derivatives after menopause may produce changes in the production of specific subunits of the $\mathrm{GABA}_{\mathrm{A}}$ receptor (Britton and Koob, 1998; Smith et al, 1993). Low levels of progesterone in PMW, who are administered E2 without a progestin (as in this study), may thus experience greater stress-related symptoms that would normally benefit from neurosteroid- $-\mathrm{GABA}_{\mathrm{A}}$ receptor interactions. The importance of the presence of progesterone in modulating stress responses is supported by a study in female rats showing that E2induced, stress-related hormonal responses are blunted in the presence of progesterone (Milenkoviæ et al, 1986). Furthermore, there is evidence that E2 itself may be $\mathrm{GABA}_{\mathrm{A}}$ receptor antagonist (Majewska, 1992), which may lead to a diminution in $\mathrm{GABA}_{\mathrm{A}}$-receptor-mediated anxiolytic effects.

\section{Limitations}

Caution is indicated in interpreting the results of this study for several reasons. The E2 dose used in this study was somewhat higher than average clinical doses, although not beyond the normal clinical range. E2 blood levels were not higher than is typically seen during the late follicular phase of a normal menstrual cycle. Integrity of the blind was somewhat difficult to maintain because of typical hormonal effects that occur in subjects taking E2 such as breast swelling or occasional breakthrough bleeding. This study was very intensive and required a significant time commitment from subjects, thus the relatively small sample size. The study sample therefore may not have been large enough to detect some effects, such as end of treatment baseline depression scores, which were trend-level different in our analysis. The TSST was repeated three times during the study although the TSST was not originally designed for repeated measures administration. It could be argued that repeated presentation would diminish the stressful response 
to the test. While there were effects of the day and scenario, the magnitude was small suggesting little habituation or sensitization, and pre-depletion and pre-TSST behavioral scores were not different between treatment groups. Furthermore, the stressful aspect of the TSST is as much the public speaking as the particular scenario used. In addition, there did not seem to be any relationship between treatment group and the incidence of adverse events following amino-acid administration and monoamine depletion. We did not perform genotyping of candidate genes (eg, serotonin transporter or $\mathrm{GABA}_{\mathrm{A}}$ ), or take detailed family histories that might be related to a negative response in this paradigm (Ellenbogen et al, 1999). We plan to do so in a follow-up study. We did not screen out subjects who reported a history of menstrual-related or perimenopausal symptoms, although we would expect that a history of such problems would be randomly distributed between both treatment groups. Finally, the average age of our subjects (mid 60s) may be important, as many of them had been without significant E2 levels for many years. Whether this data can be extrapolated to the younger women more typically given postmenopausal E2 subsequent to the WHI studies (Resnick et al, 2004; Shumaker et al, 2004) is unclear. FSH levels were similar at baseline in both groups and of course were different after 3 months of E2 or placebo treatment. Whether the difference in FSH levels could have indirectly affected the results of this stress maneuver or monoamine depletion in this study is unclear. Increased variability of FSH levels in some studies have been associated with higher depression scores in perimenopausal women (Freeman et al, 2006), but not in others (Dennerstein et al, 2007).

\section{SUMMARY}

In all, 15 PMW who were administered E2 for 3 months exhibited marked worsening of mood and cognitive performance after a social stress test compared to placebo-treated PMW. These effects were independent of tryptophan or tyrosine/phenylalanine depletion. These results suggest that the effects of E2 on behavior are complex, and that the hormonal milieu may affect the response to stressful life events, at least in PMW. These data imply that the particular dose of E2 administered to PMW may be important in determining mood reactivity, especially to stressful events, and, taken with prior research, suggest that the effects of E2 on mood reactivity may not be linear. Effects of the hormone-stress interaction did not appear to be mediated directly through catecholamine or indoleamine mechanisms. Further research will be necessary to confirm and clarify these findings as well as to explore underlying mechanisms. Replication without the depletion maneuver, the examination of the effects of different doses of E2, combined E2 and progestin therapy, and the examination of women during different phases of the menstrual cycle will help clarify these findings.

\section{ACKNOWLEDGEMENTS}

This work was supported by an independent investigator award from NARSAD and R01 AG021476 to PN, CIHR grant
MOP-150051 to SNY, and GCRC M01-00109. None of the sponsors had any role in the design or conduct of the study, management, analysis, and interpretation of the data, or preparation, review, or approval of the manuscript. We thank Dori Weigand, RNC, MSN, Judy Kerr, RN, and the staff of the University of Vermont General Clinical Research Center for their efforts in support of this project and our research volunteers for their dedication to clinical research.

\section{DISCLOSURE}

Dr Newhouse acknowledges that he is on Speaker Bureaus for Forest and Pfizer and has received research support (not for this project) in the last 12 months from Astellas, Pfizer, and Wyeth. Drs Sites, Dumas, Benkelfat, Naylor, Young, and Ms Hancur-Bucci report no potential conflicts.

\section{REFERENCES}

Amin Z, Epperson CN, Constable RT, Canli T (2006a). Effects of estrogen variation on neural correlates of emotional response inhibition. Neuroimage 32: 457-464.

Amin Z, Gueorguieva R, Cappiello A, Czarkowski KA, Stiklus S, Anderson GM et al (2006b). Estradiol and tryptophan depletion interact to modulate cognition in menopausal women. Neuropsychopharmacology 31: 2489-2497.

Baumann G (1983). Estrogens and the hypothalamo-pituitaryadrenal axis in man: evidence for normal feedback regulation by corticosteroids. J Clin Endocrinol Metab 57: 1193-1197.

Bebbington PE, Dunn G, Jenkins R, Lewis G, Brugha T, Farrell M et al (1998). The influence of age and sex on the prevalence of depressive conditions: report from the national survey of psychiatric morbidity. Psychol Med 28: 9-19.

Beck AT, Ward CH, Mendelson M, Mock J, Erbaugh J (1961). An inventory for measuring depression. Arch Gen Psychiatry 4: 53-63.

Best N, Rees MP, Barlow DH, Cowen PJ (1992). Effect of estradiol implant on noradrenergic function and mood in menopausal subjects. Psychoneuroendocrinology 17: 87-93.

Bethea CL, Mirkes SJ, Lu NZ, Streicher JM, Cameron JL (2003). Differences in central serotonergic activity in stress-sensitive vs stress-resilient monkeys: tryptophan hydroxylase (TPH), serotonin reuptake transporter (SERT) and serotonin 1A autoreceptor (5HT1A) mRNA expression. The Society of Biological Psychiatry 2003, Annual Meeting. San Francisco, CA, p 558.

Beyenburg S, Stoffel-Wagner B, Bauer J, Watzka M, Blumcke I, Bidlingmaier F et al (2001). Neuroactive steroids and seizure susceptibility. Epilepsy Res 44: 141-153.

Björn I, Sunderstrom-Poromaa I, Bixo M, Nyberg S, Backstrom G, Backstrom T (2003). Increase of estrogen dose deteriorates mood during progestin phase in sequential hormonal therapy. J Clin Endocrinol Metab 88: 2026-2030.

Britton KT, Koob GF (1998). Premenstrual steroids? Nature 392: 869-870.

Burleson MH, Malarkey WB, Cacioppo JT, Poehlmann KM, KiecoltGlaser JK, Berntson GG et al (1998). Postmenopausal hormone replacement: effects on autonomic, neuroendocrine, and immune reactivity to brief psychological stressors. Psychosom Med 60: 17-25.

Carey MP, Deterd CH, de Koning J, Helmerhorst F, de Kloet ER (1995). The influence of ovarian steroids on hypothalamicpituitary-adrenal regulation in the female rat. J Endocrinol 144: 311-321.

Caspi A, Sugden K, Moffitt TE, Taylor A, Craig IW, Harrington H et al (2003). Influence of life stress on depression: moderation by a polymorphism in the 5-HTT gene. Science 301: 386-389. 
Ceresini G, Freddi M, Morganti S, Rebecchi I, Modena AB, Rinaldi $M$ et al (2000). The effects of transdermal estradiol on the response to mental stress in postmenopausal women: a randomized trial. Am J Med 109: 463-468.

Cohen LS, Soares CN, Vitonis AF, Otto MW, Harlow BL (2006). Risk for new onset of depression during the menopausal transition: the Harvard study of moods and cycles. Arch Gen Psychiatry 63: 385-390.

Cummings JA, Brizendine L (2002). Comparison of physical and emotional side effects of progesterone or medroxyprogesterone in early postmenopausal women. Menopause 9: 253-263.

Delgado P (2006). Monoamine depletion studies: implications for antidepressant discontinuation syndrome. J Clin Psychiatry 67(Suppl 4): 22-26.

Dennerstein L, Lehert P, Burger HG, Guthrie JR (2007). New findings from non-linear longitudinal modeling of menopausal hormone changes. Hum Reprod Update: doi:10.1093/humupd/ dmm022.

Ellenbogen MA, Young SN, Dean P, Palmour RM, Benkelfat C (1996). Mood response to acute tryptophan depletion in healthy volunteers: sex differences and temporal stability. Neuropsychopharmacology 15: 465-474.

Ellenbogen MA, Young SN, Dean P, Palmour RM, Benkelfat C (1999). Acute tryptophan depletion in healthy young women with a family history of major affective disorder. Psychol Med 29: 35-46.

Fink G, Sumner BEH, Rosie R, Grace O, Quinn JP (1996). Estrogen control of central neurotransmission: effect on mood, mental state, and memory. Cell Mol Neurobiol 16: 325-344.

First MB, Spitzer RL, Gibbon M, Williams JBW (2001). Structured Clinical Interview for DSM-IV-TR Axis I Disorders-Patient Edition, SCID-I/P, 21/2001 edn. American Psychiatric Press Inc: Washington, DC.

Folstein MF, Folstein SE, McHugh PR (1975). 'Mini-mental state': a practical method for grading the cognitive state of patients for the clinician. J Psychiatr Res 12: 189-198.

Freeman EW, Sammel MD, Lin H, Nelson DB (2006). Associations of hormones and menopausal status with depressed mood in women with no history of depression. Arch Gen Psychiatry 63: 375-382.

Goldfien A, Monroe S (1983). The Ovaries. In: Greenspan F, Forsham P (eds). Basic and Clinical Endocrinology. Lange: Los Altos, CA, pp 368-413.

Goldstein JM, Jerram M, Poldrack R, Ahern T, Kennedy DN, Seidman LJ et al (2005a). Hormonal cycle modulates arousal circuitry in women using functional magnetic resonance imaging. J Neurosci 25: 9309-9316.

Goldstein KM, Harpole LH, Stechuchak KM, Coffman CJ, Bosworth HB, Steffens DC et al (2005b). Hormone therapy does not affect depression severity in older women. Am J Geriatr Psychiatry 13: 616-623.

Golightly KL, Lloyd JA, Hobson JE, Gallagher P, Mercer G, Young AH (2001). Acute tryptophan depletion in schizophrenia. Psychol Med 31: 75-84.

Grigoriadis S, Kennedy SH (2002). Role of estrogen in the treatment of depression. Am J Ther 9: 503-509.

Halbreich U, Rojansky N, Palter S, Tworek H, Hissin P, Wang K (1995). Estrogen augments serotonergic activity in postmenopausal women. Biol Psychiatry 37: 434-441.

Harrison BJ, Olver JS, Norman TR, Burrows GD, Wesnes KA, Pradeep NJ (2004). Selective effects of acute serotonin and catecholamine depletion on memory in healthy women. Int $J$ Neuropsychopharmacol 18: 32-40.

Hays J, Ockene JK, Brunner R, Kotchen JM, Manson JE, Patterson RE et al (2003). Effects of estrogen plus progestin on health-related quality of life. N Engl J Med 348: 1839-1854.

Hlatky MA, Boothroyd D, Vittinghoff E, Sharp P, Whooley MA, for the HRG (2002). Quality-of-life and depressive symptoms in postmenopausal women after receiving hormone therapy: results from the heart and estrogen/progestin replacement study (HERS) trial. JAMA 287: 591-597.

Jurica PJ, Leitten CL, Mattis S (2001). Dementia Rating Scale-2. Psychological Assessment Resources Inc.: Lutz, FL.

Kajantie E, Phillips DIW (2006). The effects of sex and hormonal status on the physiological response to acute psychosocial stress. Psychoneuroendocrinology 31: 151.

Kessler RC, McGonagle KA, Zhao S, Nelson CB, Hughes M, Eshleman $S$ et al (1994). Lifetime and 12-month prevalence of DSM-III-R psychiatric disorders in the United States. Arch Gen Psychiatry 51: 8-19.

Kirschbaum C, Pirke KM, Hellhammer DH (1993). The 'Trier Social Stress Test' - a tool for investigating psychobiological stress responses in a laboratory setting. Neuropsychobiology 28: 76-81.

Kirschbaum C, Prussner JC, Stone AA, Federenko I, Gaab J, Lintz $\mathrm{D}$ et al (1995). Persistent high cortisol responses to repeated psychological stress in a subpopulation of healthy men. Psychosom Med 57: 468-474.

Komesaroff PA, Esler MD, Sudhir K (1999). Estrogen supplementation attenuates glucocorticoid and catecholamine responses to mental stress in perimenopausal women. J Clin Endocrinol Metab 84: 606-610.

Kudielka BM, Schmidt-Reinwald AK, Hellhammer DH, Kirschbaum C (1999). Psychological and endocrine responses to psychosocial stress and dexamethasone/corticotropin-releasing hormone in healthy postmenopausal women and young controls: the impact of age and a two-week estradiol treatment. Neuroendocrinology 70: 422-430.

Kugaya A, Epperson CN, Zoghbi S, van Dyck CH, Hou Y, Fujita M et al (2003). Increase in prefrontal cortex serotonin $2 \mathrm{~A}$ receptors following estrogen treatment in postmenopausal women. Am J Psychiatry 160: 1522-1524.

Leyton M, Young SN, Pihl RO, Etezadi S, Lauze C, Blier P et al (1999). Effects on mood of acute phenylalanine/tyrosine depletion in healthy women. Neuropsychopharmacology 22: $52-63$.

Lindheim SR, Legro RS, Bernstein L, Stanczyk FZ, Vijod MA, Presser SC et al (1992a). Behavioral stress responses in premenopausal and postmenopausal women and the effects of estrogen. American Journal of Obstetrics and Gynecology 167: $1831-1836$

Lindheim SR, Legro RS, Bernstein L, Stanczyk FZ, Vijod MA, Presser SC et al (1992b). Behavioral stress responses in premenopausal and postmenopausal women and the effects of estrogen. Am J Obstet Gynecol 167: 1831-1836.

Lindheim SR, Legro RS, Morris RS, Wong IL, Tran DQ, Vijod MA et al (1994). The effect of progestins on behavioral stress responses in postmenopausal women. J Social Gynecol Invest 1: 79-83.

Magiakou MA, Mastorakos G, Webster E, Chrousos GP (1997). The hypothalamic-pituitary-adrenal axis and the female reproductive system. Ann NY Acad Sci 816: 42-56.

Majewska MD (1992). Neurosteroids: endogenous bimodal modulators of the GABAA receptor. Mechanism of action and physiological significance. Prog Neurobiol 38: 379-395.

Matthews KA, Owens JF, Salomon K, Harris KF, Berga SL (2005). Influence of hormone therapy on the cardiovascular responses to stress of postmenopausal women. Biol Psychol 69: 39.

McDermott JL, Kreutzberg JD, Liu B, Dluzen DE (1994). Effects of estrogen treatment on sensorimotor task performance and brain dopamine concentrations in gonadectomized male and female CD-1 mice. Horm Behav 28: 16-28.

McEwen B (2002). Estrogen actions throughout the brain. Recent Prog Horm Res 57: 357-384.

McNair DM, Lorr M, Droppleman LF (1971). Profile of Mood States. Educational and Industrial Testing Service: San Diego, CA. 
Milenkoviæ L, Bogiæ L, Martinoviæ JV (1986). Effect of oestradiol and progesterone on stress-induced secretion of prolactin in ovarectomized and/or adrenalectomized female rats. Acta Endocrinol 112: 79-82.

Miller KJ, Conney JC, Rasgon NL, Fairbanks LA, Small GW (2002). Mood symptoms and cognitive performance in women estrogen users and nonusers and men. J Am Geriatr Soc 50: 1826-1830.

Morrison MF, Kallan MJ, Ten Have T, Katz I, Tweedy K, Battistini $M$ (2004). Lack of efficacy of estradiol for depression in postmenopausal women: a randomized, controlled trial. Biol Psychiatry 55: 406-412.

Nagata H, Nozaki M, Nakano H (2005). Short-term combinational therapy of low-dose estrogen with selective serotonin re-uptake inhibitor (fluvoxamine) for oophorectomized women with hot flashes and depressive tendencies. J Obstet Gynaecol Res 31: 107-114.

Overall J, Gorham D (1993). The brief psychiatric rating scale. Psychol Rep 10: 799-812.

Palinkas LA, Barrett-Connor E (1992). Estrogen use and depressive symptoms in postmenopausal women. Obstet Gynecol 80: 30-36.

Pearson R, Lewis MB (2005). Fear recognition across the menstrual cycle. Horm Behav 47: 267-271.

Porter RJ, Phipps AJ, Gallagher P, Scott A, Stevenson PS, O’Brien JT (2005). Effects of acute tryptophan depletion on mood and cognitive functioning in older recovered depressed subjects. Am $J$ Geriatr Psychiatry 13: 607-615.

Prior JC (1998). Perimenopause: the complex endocrinology of the menopausal transition. Endocr Rev 19: 397-428.

Protopopescu X, Pan H, Altemus M, Tuescher O, Polanecsky M, McEwen B et al (2005). Orbitofrontal cortex activity related to emotional processing changes across the menstrual cycle. Proc Natl Acad Sci USA 102: 16060-16065.

Rasgon NL, Altshuler LL, Fairbanks LA, Dunkin JJ, Davtyan C, Elman $S$ et al (2002). Estrogen replacement therapy in the treatment of major depressive disorder in perimenopausal women. J Clin Psychiatry 63: 42-48.

Rasgon NL, Dunkin J, Fairbanks L, Altshuler LL, Troung C, Elman $S$ et al (2007). Estrogen and response to sertraline in postmenopausal women with major depressive disorder: a pilot study. J Psychiatr Res 41: 338-343.

Reisberg B, Ferris SH, de Leon MJ, Crook T (1993a). The global deterioration scale for assessment of primary degenerative dementia. Am J Psychiatry 139: 1136-1139.

Reisberg B, Ferris S (1988). Brief Cognitive Rating Scale (BCRS). Psychopharmacol Bull 24: 629-636.

Resnick SM, Coker LH, Maki PM, Rapp PR, Espeland MA, Shumaker SA (2004). The women's health initiative study of cognitive aging (WHISCA): a randomized clinical trial of the effects of hormone therapy on age-associated cognitive decline. Clin Trials 1: 440-450.

Resnick SM, Maki PM, Rapp SR, Espeland MA, Brunner R, Coker LH et al (2006). Effects of combination estrogen plus progestin hormone treatment on cognition and affect. J Clin Endocrinol Metab 91: 1802-1810.

Rohleder N, Schommer NC, Hellhammer DH, Engel R, Kirschbaum C (2001). Sex differences in glucocorticoid sensitivity of proinflammatory cytokine production after psychosocial stress. Psychosom Med 63: 966-972.

Roy BN, Reid RL, Van Vugt DA (1999). The effects of estrogen and progesterone on corticotropic-releasing hormone and arginine vasopressin messenger ribonucleic acid levels in paraventricular nucleus and supraoptic nucleus of the rhesus monkey. Endocrinology 140: 2191-2196.

Rubinow D, Schmidt P, Roca C (1993). Estrogen-serotonin interactions: implications for affective regulation. Biol Psychiatry 44: 839-850.

Saab PG, Matthews KA, Stoney CM, McDonald RH (1989). Premenopausal and postmenopausal women differ in their cardiovascular and neuroendocrine responses to behavioral stressors. Psychophysiology 26: 270-280.

Schleifer LA, Justice AJ, de Wit H (2002). Lack of effects of acute estradiol on mood in postmenopausal women. Pharmacol, Biochem Behav 71: 71-77.

Schmidt PJ, Nieman L, Danaceau MA, Tobin MB, Roca CA, Murphy JH et al (2000). Estrogen replacement in perimenopause-related depression: a preliminary report. Am J Obstet Gynecol 183: 414-420.

Schneider LS, Small GW, Hamilton SH, Bystritsky A, Nemeroff CB, Meyers BS (1993). Estrogen replacement and response to fluoxetine in a multicenter geriatric depression trial. $A m \mathrm{~J}$ Geriatr Psychiatry 5: 97-106.

Shansky RM, Glavis-Bloom C, Lerman D, McRae P, Benson C, Miller K et al (2004). Estrogen mediates sex differences in stressinduced prefrontal cortex dysfunction. Molecular Psychiatry 9: 531-538.

Sherwin BB (1991). The impact of different doses of estrogen and progestin on mood and sexual behavior in postmenopausal women. J Clin Endocrinol Metab 72: 336-343.

Shumaker SA, Legault C, Kuller L, Rapp SR, Thal L, Lane DS et al (2004). Conjugated equine estrogens and incidence of probable dementia and mild cognitive impairment in postmenopausal women. J Am Med Assoc 291: 2947-2957.

Smith SS, Gong QH, Hsu FC, Markowitz RS, ffrench-Mullen JM, Li X (1993). GABA(A) receptor alpha4 subunit suppression prevents withdrawal properties of an endogenous steroid. Nature 392: 926-930.

Soares CN, Poitras JR, Prouty J (2003a). Effect of reproductive hormones and selective estrogen receptor modulators on mood during menopause. Drugs Aging 20: 85-100.

Soares CN, Poitras JR, Prouty J, Alexander AB, Shifren JL, Cohen LS (2003b). Efficacy of citalopram as a monotherapy or as an adjunctive treatment to estrogen therapy for perimenopausal and postmenopausal women with depression and vasomotor symptoms. J Clin Psychiatry 64: 473-479.

Steiner M, Dunn E, Born L (2003). Hormones and mood: from menarche to menopause and beyond. J Affect Disord 74: 67-83.

Stoppe G, Doren M (2002). Critical appraisal of effects of estrogen replacement therapy on symptoms of depressed mood. Arch Women's Ment Health 5: 39-47.

Vamvakopoulos NC, Chrousos GP (1993). Evidence of direct estrogenic regulation of human corticotropic-releasing hormone gene expression. J Clin Invest 92: 1896-1902.

Voss S, Quail D, Dawson A, Backstrom T, Aguas F, Erenus M et al (2002). A randomised, double-blind trial comparing raloxifene $\mathrm{HCl}$ and continuous combined hormone replacement therapy in postmenopausal women: effects on compliance and quality of life. BJOG: Int J Obstet Gynaecol 109: 874-885.

Weissman M, Myers J (1993). Depression in the elderly: research directions in psychopathology, epidemiology, and treatment. $J$ Geriatr Psychiatry 12: 187-201.

Whooley MA, Grady D, Cauley JA (2000). Postmenopausal estrogen therapy and depressive symptoms in older women. J Gen Intern Med 15: 535-541.

Wood GE, Shors TJ (1998). Stress facilitates classical conditioning in males, but impairs classical conditioning in females through activational effects of ovarian hormones. Proc Natl Acad Sci 95: 4066-4071.

Young S, Leyton M (1993). The role of serotonin in human mood and social interaction: insight from altered tryptophan levels. Pharmacol Biochem Behav 71: 857-865.

Young SN, Smith SE, Pihl RO, Ervin FR (1993). Tryptophan depletion causes a rapid lowering of mood in normal males. Psychopharmacology 87: 173-177.

Zweifel JE, O'Brien WH (1997). A meta-analysis of the effect of hormone replacement therapy upon depressed mood. Psychoneuroendocrinology 22: 189-212. 